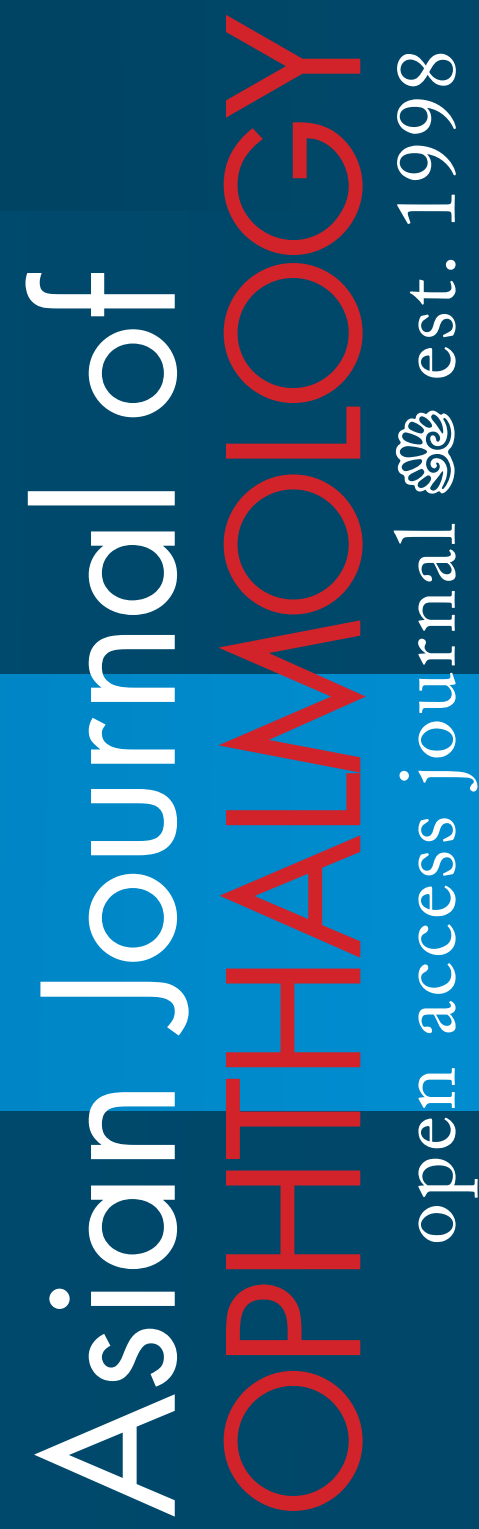

Volume $13 \cdot$ Issue $4 \cdot 2014 \cdot 1560-2133$ 


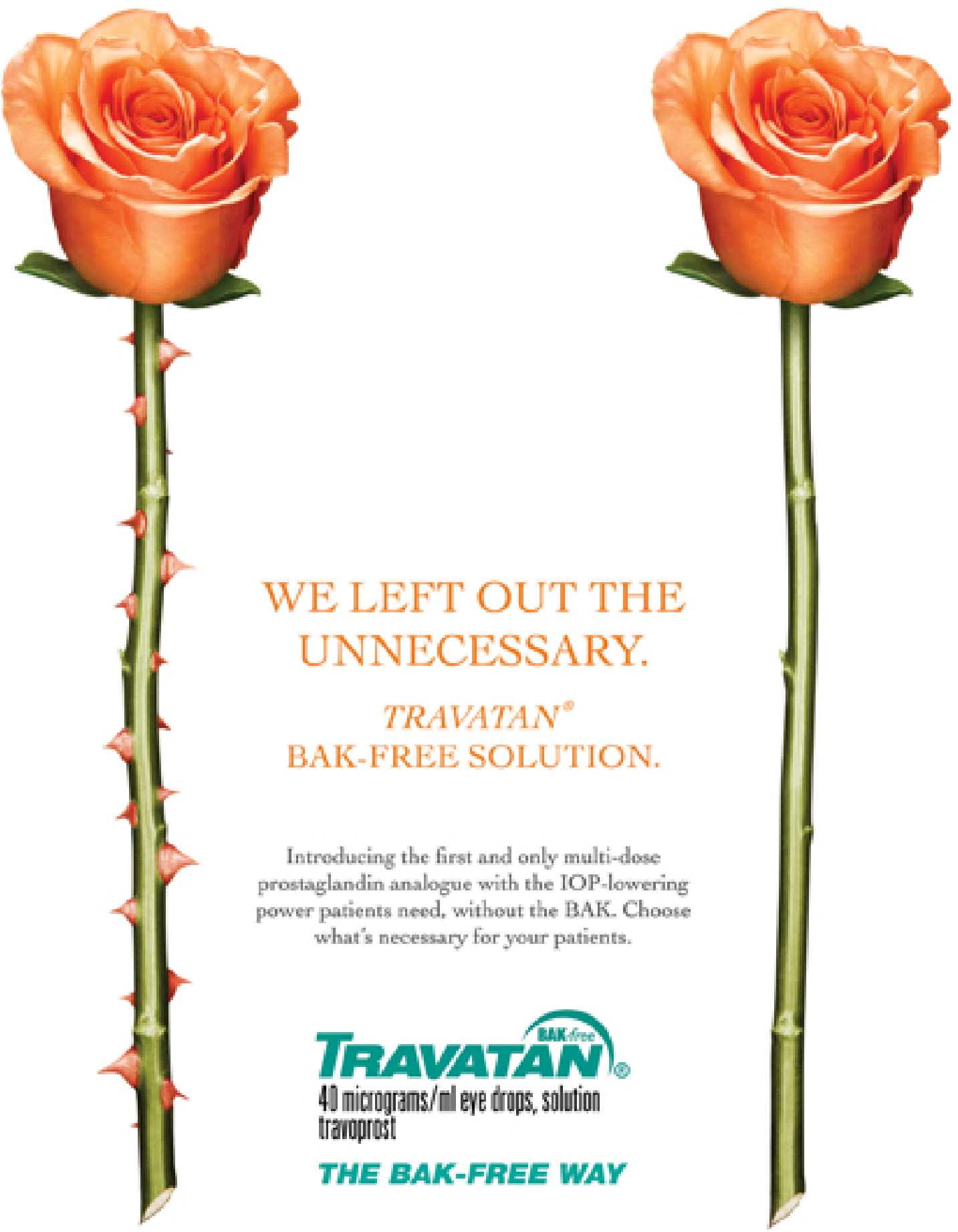

For more information on the product please contact your local Alcon' representative 


\section{Asian Journal of OPHTHALMOLOGY}

Submit your article now to the

Asian Journal of

a peer-reviewed online open access journal.

There are no publication costs, hidden fees or charges.

\section{Chief editor: Paul Chew}

The objectives of Asian Journal of Ophthalmology are as follows:

- To provide a platform for the publication of information with a focus on Ophthalmology in Asia

- To disseminate information that will improve the care of patients with all types of ophthalmological disorders, with a special focus on glaucoma

- To increase the understanding of such disorders through reporting of educational activities

- To publish the results of research programmes to expand knowledge about the causes, prevention, and treatment of ophthalmological disorders

- To work closely with Asian and international researchers to achieve these aims

- To provide a forum for young and relatively inexperienced researchers to present their research results as Original Articles via an international platform

- To maintain and promote relationships with any organisation with similar goals.

For more information, an article template and submission guidelines, see www.asjoo.com

PUBLICATION SCHEDULE 2014-2015:

2014

September 2014

September 2014

October 2014

December 2014

14-1

Highlights print issue

(APGC)

14-2

14-3
2015

February $2015 \quad$ 14-4: Special issue on

Generic Medications

April 2015

July 2015

October 2015

January 2016
15-1

15-2

15-3

15-4

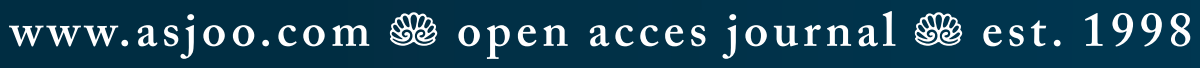




\title{
Epidemiology of ocular trauma hospital presentations in Sydney, Australia: insights for management and prevention
}

\author{
Georgina C. Clark, ${ }^{1,2}$ Trent M. Sandercoe, ${ }^{1}$ Somsak Lertsumitkul, ${ }^{1}$ \\ Magdalena Guzowski, ${ }^{1}$ Peter J. McCluskey ${ }^{1,2}$ \\ 'Department of Ophthalmology, Liverpool Hospital, Liverpool, NSW, Australia; \\ ${ }^{2}$ Save Sight Institute, Discipline of Ophthalmology and Eye Health, Sydney, \\ Australia
}

\begin{abstract}
Aim: To facilitate care delivery and injury prevention by investigating the nature and outcomes of ocular trauma presentations to a tertiary care center serving an estimated 1.3 million people.

Patients and methods: This is an observational case series, retrospectively analyzed, of all patients that presented to the tertiary care center for management of ocular trauma between 01/01/2006-31/12/2006. Data collected included: patient's clinical findings, major diagnoses, initial and final visual acuity, whether the injury was work related, whether protective eyewear was worn, and whether the patient required surgery or admission to hospital. A final BCVA $<6 / 12$ was defined as significant visual deficit.

Eligible patients were identified prospectively by researchers. Patients underwent standardized clinical assessment. De-identified clinical data was entered into a Microsoft Access database retrospectively and analyzed by separate, blinded researchers. Descriptive statistical analysis was then performed in Microsoft Excel. Analysis based on an ordinal regression model and risk factor analysis was performed in SAS.

Results: There were 214 cases of ocular trauma in 197 individuals (17 bilateral injuries). Patients were mostly male (83\%) with average age 35 . The majority of cases were closed globe injuries (92.1\%) with no significant final visual deficit (88.3\%). Open globe injuries (7.9\%) were more likely to have visual deficit (i.e., $47 \%$ with final BCVA $<6 / 12)(p<0.01)$. In total, $13.1 \%$ required surgery and $12.1 \%$ required admission to hospital. Eye protection was worn in $7.9 \%$ of all cases, and $19.1 \%$ of work related cases. Nearly one quarter of cases (22.4\%) were work related. Open globe injuries were more likely to occur at work. Open globe injuries at work were caused by a metal projectile in $85.7 \%$ of cases. Thirty percent of workers suffered a burn, with final BCVA $<6 / 12$ in $10 \%$ of burns.

Conclusions: While the vast majority of ocular trauma is superficial with low morbidity, trauma persists as a significant cause of visual impairment. Most vision impairing injuries occur at work, where metal projectiles and burns are common, preventable causes of significant vision loss, which could be targeted in prevention efforts.
\end{abstract}

Key words: Ocular, trauma, epidemiology

Correspondence: Dr. Georgina Clark, c/o Professor McCluskey, Save Sight Institute, GPO Box 4337, Sydney 2001, Australia. E-mail: ggclark@hotmail.com 


\section{Introduction}

Eye injury is a significant cause of morbidity and economic burden to the community. ${ }^{1}$ A 1995 study by Fong conservatively estimated the annual cost in Australia at $\$ 155$ million. ${ }^{2}$ Twenty percent of the population were found to have suffered eye injury in their lifetime according to McCarty et al., ${ }^{3}$ slightly higher than a lifetime prevalence of ocular injury in the United States of $14.4 \%-19.8 \% .{ }^{4,5}$ Annual incidence of eye injury has been estimated at 11.4 per 1000 of population. ${ }^{2,6}$ The incidence of hospitalized eye injuries was found to be 15.3 per 100,000. ${ }^{7}$

The purpose of this study is to investigate the etiology, clinical features, and resulting visual impairment related to ocular trauma in South West Sydney, in order to inform delivery of care and injury prevention efforts. Region specific studies of ocular trauma are important since socioeconomic and demographic variables are significantly correlated with injury frequency and severity. ${ }^{6,7}$ Additionally, the study region is significant due to its size, covering a catchment area of 1.35 million people, or $6.5 \%$ of the Australian population. ${ }^{8,9}$

\section{Patients and methods}

The study is an observational case series of all patients presenting to Liverpool Hospital, including those directly referred to the Liverpool Ophthalmology Department clinic, with ocular trauma during 2006. Participants were referred into the study by treating clinicians in the Emergency Department and Ophthalmology Clinic, and the Emergency triage database was periodically reviewed to identify potentially missed cases. All patients presenting to the care of tertiary hospital ophthalmology department in this manner between 01/01/2006 and 31/12/2006 were considered to meet the inclusion criteria of the study. The exclusion criteria were absence of ocular trauma during the study period, or death prior to ophthalmic assessment, for example due to multi-system trauma.

Patients underwent standardized assessment of ocular trauma, as per the training guidelines of the Royal Australian and New Zealand College of Ophthalmology (RANZCO). This comprised of history taking and an examination including external examination, orbital and full ocular examination for all patients, with subsequent further examination and investigations, including imaging, tailored to clinical findings and suspicion, in keeping with RANZCO training guidelines. Management was also appropriate to diagnosis as per RANZCO training guidelines.

All ocular examination findings were recorded, including initial best corrected visual acuity (BCVA), and final BCVA. For the purposes of statistical analysis, a final $B C V A<6 / 12$ was defined as a significant deficit in BCVA. Other variables recorded were: patient demographics, diagnosis, open globe injury etiology, whether the injury was work related, whether protective eyewear was worn, and finally whether the patient required surgery or admission to hospital (under the care of an ophthalmologist).

De-identified clinical data was entered into a Microsoft Access database retrospectively and analyzed, by separate, blinded researchers. The ocular trauma was 
categorized according to Kuhn's classification of ocular trauma into either open globe or closed globe injuries, with further sub-classification by clinical diagnosis (10). Descriptive statistical analysis was then performed in Microsoft Excel. Analysis based on an ordinal regression model and risk factor analysis was performed in SAS (version 9.2).

This study was conducted with the approval of the Human Research Ethics Committee, Liverpool Hospital. The study was conducted as per the tenets of the Helsinki Declaration.

\section{Results}

\section{General overview}

One hundred ninety-seven individuals presented to Liverpool Hospital with ocular trauma to 214 eyes (17 bilateral injuries). For the purposes of this study, each eye injured was considered a single 'case', with bilateral eye injury counted as two cases.

\section{Age and sex}

The average patient age was $35.4( \pm 17.1)$ years. Patients were predominantly male (83\%). The average patient age was lower in females (32.9 years) than males (35.8 years).

\section{Nature of Injuries}

The majority of injuries were closed globe (197 eyes or $92.1 \%)$. The relative frequency of ocular examination findings are listed in Table 1. Occasionally, a single eye had multiple clinical findings. Thus, in total there were 250 clinical findings in 214 injured eyes in 197 patients. Table 1 lists the number of eyes with each clinical finding, as well as the proportion of all 250 findings this represented.

Orbital trauma was the most common finding, recorded in a fifth of all cases. The vast majority of these were orbital wall fractures ( 47 of 50 orbit trauma cases). Lacerations, to the conjunctiva, cornea or sclera comprised $17 \%$ of findings. Iris trauma (12\%) was relatively common. Retinal trauma was observed in $10.0 \%$, and lenticular trauma in $4.4 \%$. Vitreous hemorrhages were rarer, observed in $2.8 \%$. Optic nerve trauma and uveal trauma each comprised of $1.6 \%$ of cases respectively.

\section{Surgery and hospitalization}

Of all cases, $13.1 \%$ required surgery, and $12.1 \%$ required admission to hospital.

\section{Eye protection}

Seventeen (7.9\%) patients reported wearing eye protection at the time of trauma. Of those injured at work, eight (19.1\%) wore eye protection.

\section{Visual outcomes}

Table 2 lists final best corrected visual acuity (BCVA) findings in three categories: (1) all eyes; (2) closed globe eyes; and (3) open globe eyes. Analyzing all eyes, 84.1\% had no significant deficit in BCVA at final examination (defined as final $B C V A \geq 6 / 12$ ). 
Table 1. Ocular examination finding frequency is listed by number of cases with each clinical finding. There were 250 findings in $\mathbf{2 1 4}$ eyes. Percentages reflect the proportion of total findings found in each category.

\begin{tabular}{|c|c|}
\hline Findings & Number of cases (\%) \\
\hline Orbit trauma & $50(20.0)$ \\
\hline - orbital wall fractures & $47(18.8)$ \\
\hline - other orbital trauma & $3(1.2)$ \\
\hline Lacerations & $43(17.2)$ \\
\hline - corneal laceration & $16(6.4)$ \\
\hline - scleral laceration & $14(5.6)$ \\
\hline - conjunctival laceration & $13(5.2)$ \\
\hline Hyphema & 39 (15.6) \\
\hline Iris trauma & $30(12.0)$ \\
\hline - traumatic mydriasis & $17(6.8)$ \\
\hline - iris prolapse & $6(2.4)$ \\
\hline - sphincter tear & $3(1.2)$ \\
\hline - other iris trauma & $4(1.6)$ \\
\hline Retinal trauma & $25(10.0)$ \\
\hline - commotio retinae & $13(5.2)$ \\
\hline - retinal hemorrhage & $4(1.6)$ \\
\hline - retinal detachment & $2(0.8)$ \\
\hline - other retinal trauma & $6(2.4)$ \\
\hline Lid trauma & $20(8.0)$ \\
\hline Raised intra ocular pressure & $16(6.4)$ \\
\hline Lens trauma & $11(4.4)$ \\
\hline Vitreous haemorrhage & $7(2.8)$ \\
\hline Uvea trauma & $4(1.6)$ \\
\hline - uveal prolapse & $3(1.2)$ \\
\hline - choroidal rupture & $1(0.4)$ \\
\hline Optic nerve trauma & $4(1.6)$ \\
\hline
\end{tabular}


Table 2. Final best corrected visual acuity (VA) of: all 214 eyes; 197 closed globe eyes; and 17 open globe eyes. Percentages, in parenthesis, describe the proportion of each group with a particular visual outcome. For the difference in final VA between closed globe and open globe cases, $p$-value $<0.001$.

\begin{tabular}{|l|l|l|l|}
\hline $\begin{array}{l}\text { Visual Outcomes: } \\
\text { Final VA }\end{array}$ & $\begin{array}{l}\text { All Injured Eyes } \\
(\%)\end{array}$ & $\begin{array}{l}\text { Closed Globe Eyes } \\
(\%)\end{array}$ & $\begin{array}{l}\text { Open Globe Eyes } \\
(\%)\end{array}$ \\
\hline VA $\geq 6 / 12$ & $180(84.1)$ & $174(88.3)$ & $6(35.3)$ \\
\hline VA <6/12 & $8(3.7)$ & $7(3.5)$ & $1(5.9)$ \\
\hline VA <6/60 & $5(2.3)$ & $2(1.0)$ & $3(17.6)$ \\
\hline NPL $^{*}$ & $7(3.3)$ & $3(1.5)$ & $4(23.5)$ \\
\hline Incomplete data & $14(6.5)$ & $11(5.6)$ & $3(17.6)$ \\
\hline
\end{tabular}

* NPL $=$ no perception of light

\section{Closed globe injuries}

There were 197 eyes (92.1\%) with closed globe injuries with an average patient age of 35.7 ( \pm 17.1 ) years, and male preponderance $(87.8 \%)$.

There were 224 closed globe diagnoses in 197 eyes, as detailed in Table 3, according to Kuhn's diagnostic categories of closed globe injuries. The most common findings were contusion (34.3\%), superficial foreign body (31.3\%), and burns (17.4\%).

Table 3: Closed globe ocular diagnosis frequency is listed by number of eyes with each clinical finding. There were 224 findings in 197 eyes. Percentages, in parenthesis, reflect the proportion of total diagnoses found in each category. Lamellar laceration includes corneal abrasion and conjunctival abrasion.

\begin{tabular}{|l|l|}
\hline Findings & Number of eyes (\% of total findings) \\
\hline Contusion & $77(34.3)$ \\
\hline Superficial Foreign Body & $70(31.3)$ \\
\hline Burns & $39(17.4)$ \\
\hline Lamellar laceration & $38(17.0)$ \\
\hline - Corneal abrasion & $36(16.1)$ \\
\hline - Conjunctival abrasion & $2(0.9)$ \\
\hline
\end{tabular}

There were 39 eyes with burns in 28 individuals. Most burns were alkali (61.5\%), then acid (15.3\%), ultraviolet (12.8\%), and thermal (10.2\%).

Visual outcomes for the closed globe group are shown in column three of Table 2. Most eyes (88.3\%) had no significant deficit of visual acuity. However, twelve (6\%) did have significant deficit, including three (1.5\%) with no perception of light (NPL) secondary to traumatic optic neuropathy.

Table 4 summarizes visual outcomes for the various diagnostic categories of 
closed globe injury. Corneal abrasions and foreign bodies while common were rarely associated with visual deficit. Burns, however, were high morbidity with a significant visual deficit in $10.2 \%$ of cases.

Table 4: Final best corrected visual acuity (VA) for various categories of closed globe eye injuries. Numbers of eyes in each category are listed. Percentages, in parenthesis, reflect the proportion of injured eyes in each diagnostic category that have a given visual outcome.

\begin{tabular}{|l|l|l|l|l|l|l|}
\hline $\begin{array}{l}\text { Visual } \\
\text { Outcomes } \\
\text { (Final VA) }\end{array}$ & Contusions & Foreign body & Burn & $\begin{array}{l}\text { Lamellar } \\
\text { laceration }\end{array}$ & $\begin{array}{l}\text { Corneal } \\
\text { abrasion }\end{array}$ & $\begin{array}{l}\text { Conjunctival } \\
\text { abrasion }\end{array}$ \\
\hline VA $\geq 6 / 12$ & $\begin{array}{l}65 \\
(84.4)\end{array}$ & $\begin{array}{l}66 \\
(94.3)\end{array}$ & $\begin{array}{l}34 \\
(87.2)\end{array}$ & $\begin{array}{l}35 \\
(92.1)\end{array}$ & $\begin{array}{l}34 \\
(94.4)\end{array}$ & 0 \\
\hline VA $<6 / 12$ & 2 & 2 & 2 & 3 & 1 & 2 \\
$(2.6)$ & $(2.9)$ & $(5.1)$ & $(7.9)$ & $(2.8)$ & $(100)$ \\
\hline VA $<6 / 60$ & $\begin{array}{l}1 \\
(1.3)\end{array}$ & $\begin{array}{l}1 \\
(1.4)\end{array}$ & $\begin{array}{l}2 \\
(5.1)\end{array}$ & 0 & 0 & 0 \\
\hline NPL & $\begin{array}{l}3 \\
(3.9)\end{array}$ & 0 & 0 & 0 & 0 & 0 \\
\hline $\begin{array}{l}\text { Incomplete } \\
\text { data }\end{array}$ & $\begin{array}{l}6 \\
(7.8)\end{array}$ & $\begin{array}{l}1 \\
(1.4)\end{array}$ & $\begin{array}{l}1 \\
(2.6)\end{array}$ & 0 & $\begin{array}{l}1 \\
(2.8)\end{array}$ & 0 \\
\hline
\end{tabular}

\section{Open globe injuries}

There were a total of seventeen patients with open globe injuries representing $7.9 \%$ of the total number of injured eyes. Penetrating globe injuries were observed in nine eyes (52.9\%) of which three also had an associated intraocular foreign body. There were five ruptured globes (29.4\%), and three full thickness lacerations (17.7\%).

The majority (80\%) of open globe injuries were in males (14 eyes). Four patients $(23.5 \%)$ were age 18 or below.

No patient wearing eye protection suffered an open globe injury, and while the findings were suggestive of an association with eye protection use and a reduced risk of open globe injury $(p=0.30)$, the sample size was not large enough to demonstrate statistical significance.

Amongst open globe cases, injury by a metal projectile was involved in seven of seventeen injuries (41.1\%), making it the most common mechanism. Six of these seven cases were work-related. The next most common mechanism was assault, with three cases (18\%). The other causes were varied including one motor vehicle accident $(6 \%)$, and one explosion.

In Table 2, column four summarizes the visual outcomes for the open globe cases. As expected, visual outcomes were worse for the open globe cases than the closed globe cases ( $p$ value $<0.001$ ). Six eyes $(35.3 \%$ ) had final $B C V A \geq 6 / 12$, the remaining eight eyes (47\%) had final BCVA $<6 / 12$ including four eyes (23.5\%) with NPL. 
Table 5 shows final BCVA for the various types of open globe injuries. The five ruptured globes (29.4\% of the open globe eyes) all had poor visual outcomes, four with NPL and one with final BCVA of $<6 / 60$. All three eyes with full thickness laceration had final $B C V A \geq 6 / 12$.

Table 5: Final best corrected visual acuity (VA) for various diagnostic categories of open globe eye injuries. Numbers of eyes in each category are listed along with the percentage, in parenthesis, of total open globe cases that they represent.

\begin{tabular}{|l|l|l|l|}
\hline $\begin{array}{l}\text { Visual Outcomes } \\
\text { (Final VA) }\end{array}$ & $\begin{array}{l}\text { Penetrating globe } \\
\text { injury }\end{array}$ & $\begin{array}{l}\text { Ruptured globe } \\
\text { injury }\end{array}$ & $\begin{array}{l}\text { Perforating globe } \\
\text { injury }\end{array}$ \\
\hline VA $\geq 6 / 12$ & $3(17.0)$ & 0 & $3(17.3)$ \\
\hline VA $<6 / 12$ & $1(5.9)$ & 0 & 0 \\
\hline VA $<6 / 60$ & $2(11.8)$ & $1(5.9)$ & 0 \\
\hline NPL & 0 & $4(23.5)$ & 0 \\
\hline Incomplete data & $3(17.6)$ & 0 & 0 \\
\hline
\end{tabular}

\section{Work-related injuries}

There were forty-nine work-related (WR) eye injuries, which represented $22.4 \%$ of all ocular trauma cases. This included two females and four bilateral injuries.

Forty-two (85.7\%) of the work-related injuries were closed globe. These were mainly superficial injuries. Superficial foreign body (SFB) was the most common finding, observed in twenty-three cases (46.9\%). Burns were the next most common with thirteen cases (30\%). Ten of the burns were alkali (77\%) and three (23\%) were ultraviolet. Work related alkali burns constituted $50 \%$ of total presentations with alkali burns. There were also eight contusions (16.3\%), and five lamellar lacerations (10.2\%).

There were seven open globe work-related injuries $(41.4 \%$ of all open globe injuries). Five (71.4\%) were penetrating eye injuries and two ruptured globes $(28.5 \%)$. All but one of the work-related open globe cases involved a metal projectile. In no case of open globe injury eye protection had been worn.

Risk factor analysis suggests open globe injuries are more commonly workrelated, albeit not quite reaching statistical significance ( $p$ value $<0.06$ ). Eight of the work-related cases (19.1\%) wore eye protection, and all of these had good visual outcomes (final BCVA ${ }^{3} 6 / 12$ ).

In $92.3 \%$ of work-related closed globe cases there was no significant deficit of final BCVA. The final visual outcomes for open globe work related cases reflected the recognized poor visual prognosis associated with open globe injuries, with two thirds of the patients suffering significant visual deficit, and nearly one third of patients with NPL. 


\section{Discussion}

This study provides insights into ocular trauma in Australia. It contributes information about frequency of different types of injury and their associated visual outcomes, injury etiology, use of eye protection and features of work place injury. These insights are useful clinically, logistically, and for injury prevention.

Regional ocular trauma studies are important due to the lack of a national ocular trauma database, and significant local variations in ocular trauma epidemiology." This study was performed in South-West Sydney, Australia, a region that warrants attention due to its size, and high risk demographic features. The 2006 population of South-West Sydney was approximately $1,350,000$ (8), or $6.5 \%$ of the Australian population. ${ }^{9}$ The area is serviced by the South-Western Sydney Local Health District and Liverpool Hospital is the district's only tertiary ophthalmology referral center. The catchment region includes five of the ten most disadvantaged local government areas of Sydney. ${ }^{12}$ Employment in the region includes industrial, manufacturing and service sectors. These work types and socioeconomic disadvantage are associated with higher risk of ocular trauma. ${ }^{13,14}$

This study's demographics findings are similar to other studies of its kind, both in Australia and abroad. Males constituted $83 \%$ of the cohort; in a similar range to previous studies (70-85\%). This is traditionally attributed to higher risk taking and occupational exposure. ${ }^{13,15}$ Average age of patients in the low thirties is also consistent with previous studies. ${ }^{6}$ Children are well known to have high rates of ocular trauma. Previous studies have found that children account for 20 to $50 \%$ of all ocular injury. ${ }^{16-18}$ In this study, $23 \%$ of the open globe injuries occurred in children.

The study demonstrates that ocular trauma commonly presents to tertiary hospital emergency departments whether the injury is low (84.1\%) or high morbidity (15.9\%). This is partly due to the pain associated with even superficial injury. Ophthalmologists are rarely the first to see an ocular trauma due to the referral system. Thus, GPs, ED staff and optometrists play an important role in emergency management of cases, which can be critical to visual outcomes. They also play an essential role in appropriately triaging which patients need to see an ophthalmologist urgently. Thus, it is vital that generalists are well-trained in ocular trauma emergency management including identification of urgent referrals.

The ratio of open globe to closed injuries was comparable with other studies in developed countries. Open globe injuries comprised $7.9 \%$ of cases, compared to $5 \%$ in a recent Singaporean study. ${ }^{15}$

This study demonstrates the heavy burden of disease associated with open globe injury. The visual outcomes were worse for the open globe cases than the closed globe cases ( $p$ value $<0.001$ ). Roughly a quarter of the open globe cases had NPL.

In this study, $22.4 \%$ of cases were work-related injuries. This is less than reported by McCarty in 1999, which was the most recent study of this kind. That study found $60 \%$ to be work related, but included a rural population. ${ }^{3}$ Another rural study found that eye injuries accounted for $12 \%$ of all injuries to the regional hospital and one third of these were work-related. ${ }^{19}$ While the discrepancies may represent 
demographic differences in the study populations, recall bias, or differences in reporting eye work-related injury, it is possible that this finding represents a true decrease in the proportion of work-related injuries. To some extent, a reduction should to be anticipated. The prevalence of worker eye injury has been on a steady decline in the western world, due to eye protection and safety standards, and a shift of many high-risk manufacturing jobs to the developing world. ${ }^{15}$

In this study, workers were more likely to sustain an open globe injury than those not injured at work, albeit with a $\mathrm{p}$ value $<0.06$. Open globe injuries are associated with the poorest visual outcomes and therefore the greatest morbidity and associated costs.

It has been estimated in the ocular trauma literature that $90 \%$ of ocular trauma is preventable. ${ }^{17}$ The prevention of eye injury amongst workers and in the general community is influenced by awareness of risk, and subsequent steps to prevent injury. One important protective measure is the use of protective eyewear. In Australia, eye protection use is governed by various standards and pieces of legislation, both at the state and national level, and is primarily focused on encouragement of eye protection use in the workplace. In Sydney, the main government bodies affecting use of eye protection by workers are Work Cover NSW and Safe Work Australia. Important legislation at the state level includes the New South Wales Occupational Health and Safety Act of 2000 and New South Wales Occupational Health and Safety Regulation of 2001. Section 8 of the Act specifies that employers must provide safe working conditions, and section 15 of the Regulations specifies that employers must provide adequate personal protective equipment, including eye protection, should a modifiable risk to employees exist. It advises that personal protective equipment should meet standards specified by Standards Australia. Key standards that apply to eye protection include AS1067, 1336, 1337, 1338, 2211, and 2397. Government bodies also provide worker education. For example, WorkCover NSW offers educational workshops for businesses, which include discussion of eye protection. An employee who does not wear available eye protection provided can be reported to WorkCover NSW for failure to cooperate, as can an employer who fails to appropriately provide eye protection.

The findings in this study suggest that people working with metal may be a worthwhile target for injury prevention campaigns. Of workers who suffered an open globe injury, $85.7 \%$ were hit by some form of metal projectile. None of these patients wore eye protection. Thompson et al. also found in their study in rural NSW that penetrating eye injuries were most commonly caused by metal projectiles, including fencing wire. ${ }^{6}$ The study by McCarty et a found that overall $30.7 \%$ of cases were caused by metal. ${ }^{3}$

The findings in this study suggest that people working with alkalis are also worthwhile targets for injury prevention efforts. Burns were a leading cause of vision loss amongst workers. Burns comprised $30 \%$ of work-related injuries, and nearly $80 \%$ of those were alkaline. Burns patients had significant visual deficit in at least $10.2 \%$ of closed globe cases. It is possible that alkali burns are becoming more common. Of all cases in this study, $11.2 \%$ suffered alkali burns, compared to $4.7 \%$ 
of the study population in McCarty's 1999 study. ${ }^{3}$ However, McCarty's study was a self-reported population-based cross-sectional study, with associated risk of recall bias. Regardless, the risk of an alkali burn, from the likes of cleaning products and cement, could be effectively reduced through more prominent warning labels and consumer education to encourage use of eye protection.

In this study, eye protection was worn in $7.9 \%$ of cases in this study, and $19.1 \%$ of work-related cases, compared to $3.2 \%$ of non-work-related cases. This study found $7.9 \%$ of the total trauma cases wore eye protection, less than the $13 \%$ reported in McCarty's 1999 study. $^{3}$ Since 1999, extensive ocular trauma prevention strategies have been implemented, including the aforementioned legislation (e.g., New South Wales Occupational Health and Safety Act of 2000) and work safety standards by Work Safe NSW and Safe Work Australia. This study is not designed to assess prevalence or effectiveness of eye protection. It primarily identifies patients who did not wear eye protection, or for whom eye protection failed, at least partially. However, future research into the effectiveness of these regulations would be valuable.

A strength of this study is that the data was collected prospectively from a single catchment area within a finite time and is therefore likely to be representative of true community presentation patterns to tertiary care.

A possible weakness of the study is that some patients may not have been captured in the database. It is possible, for example, that some minor cases of ocular trauma seen in the emergency department were not registered in the study. While this study contributes to the epidemiology knowledge base, individual studies at individual centers are prone to bias. Also, data is incomplete, with respect to final BCVA in $6.5 \%$ of eyes.

This study provides useful clinical and public health insights into ocular trauma injury patterns in metropolitan Australia by contributing information about injury relative frequency, causation, visual outcomes, burden of disease, use of eye protection and features of work place injury. There is a significant loss of vision related to open globe injury from metal projectiles and closed globe injuries from burns, especially alkali burns. Given the morbidity and relative frequency of these injuries, they are worthy of consideration for targeted prevention efforts.

\section{Acknowledgements}

The statistical analysis was kindly performed by Ms Diana Zannino (MSc), NHMRC Trials Centre, University of Sydney. No financial grants or other funding were used in this research study. None of the authors have a conflict of interest or commercial interest in relation to this article.

\section{References}

1. McGwin, G Jr, Hall, TA, Xie, A, Owsley, C. Trends in eye injury in the United States, 1992-2001. Invest Ophthalmol Vis Sci 2006;47(2):521-527.

2. Fong LP. Eye injuries in Victoria, Australia. Med J Aust 1995;162(2):64-68.

3. McCarty, CA, Fu CL, Taylor HR. Epidemiology of ocular trauma in Australia. Ophthalmology 1999;106(9):1847-1852. 
4. Katz J, Tielsch JM. Lifetime prevalence of ocular injuries from the Baltimore Eye Survey. Arch Ophthalmol 1993;111:1564-1568.

5. Wong TY, Klein BE, Klein R. The prevalence and 5-year incidence of ocular trauma. The Beaver Dam Eye Study. Ophthalmology 2000;107:2196-2202.

6. Thompson CG, Kumar N, Billson FA, Martin F. The aetiology of perforating ocular injuries in children. Br J Ophthalmol 2002;86(8):920-922.

7. Fong, LP, Taouk Y. The role of eye protection in work related eye injuries. Aust N Z J Ophthalmol 1995;23(2):101-106.

8. Department of Infrastructure, Planning and Natural Resources. New South Wales State and Regional Population Projections 2001-2031. 2005 Release. Sydney: Transport and Population Data Centre 2004.

9. Australian Bureau of Statistics. Australian Historical Population Statistics, 2008, ABS Catalogue no. 3105.0.65.001. Canberra: ABS, 2008.

10. Kuhn F, Morris R, Witherspoon CD, Heimann K, Jeffers JB , Treister G. A standardized classification of ocular trauma. Ophthalmology 1996;103(2):240-243.

11. Smith, AR, O'Hagan, SB, Gole, GA. Epidemiology of open- and closed- globe trauma presenting to Cairns Base Hospital, Queensland. Clin Experiment Ophthalmol 2006;34:252-259.

12. Australian Bureau of Statistics. Socio-Economic Indexes for Areas (SEIFA) - Technical Paper, 2006, ABS Catalogue no. 2039.0.55.001. Canberra: ABS, 2008.

13. Theylors B. Epidemiological patterns of ocular trauma. Aust NZ J Ophthalmol 1992;20(2):95-98.

14. Peate, WF. Work-related eye injuries and illnesses. Am Fam Physician 2007;75(7):1017-1022.

15. Woo J, Sundar G. Eye Injuries in Singapore - don't risk it. Do more. A Prospective Study. Ann Acad Med Singapore 2006;35(10):706-718.

16. Punnonen, E. Epidemiological and social aspects of perforating eye injuries. Acta Ophthalmol 1989;62:378-390.

17. Blomdahl, S, Staffan, N. Perforating eye injury in the Stockholm population. An epidemiological study. Acta Ophthalmol 1984;62:378-390.

18. Moriera, CA, Debert-Ribeiro, M, Belfort, R. Epidemiological study of eye injuries in Brazilian children. Arch Ophthalmol 1988;106:781-784.

19. Valuri J, Routley, V. Injury surveillance and prevention in the Latrobe Valley. Hazard 1994;1-16. 


\section{Xalatan: $\mid$ Xalacom}

\section{Efizer}

\section{One Drop a day helps them see what matters most..$^{1-4}$}

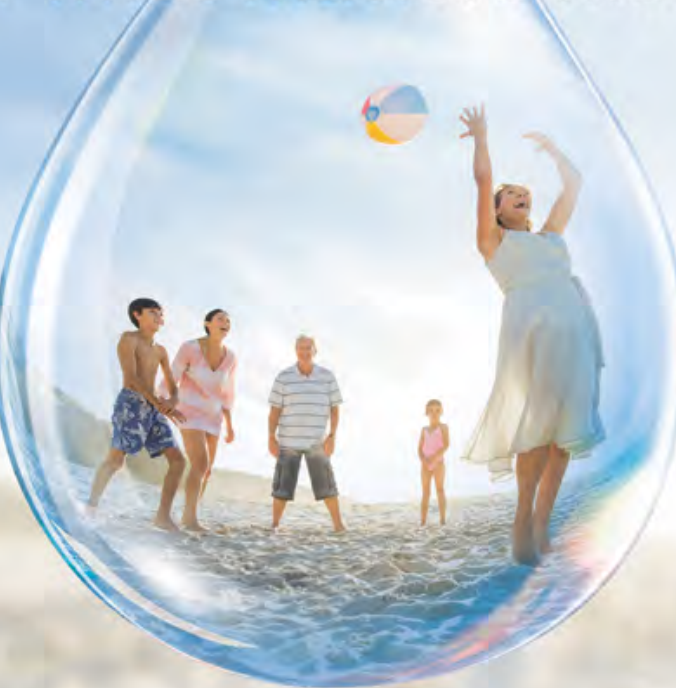

For over 10 years, Xalatan $^{\circledR}$ and Xalacom ${ }^{\circledR}$ have offered patients effective glaucoma treatments with the convenience of one bottle, one drop, once a day. ${ }^{1-4}$

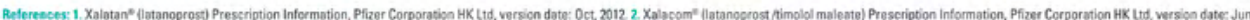

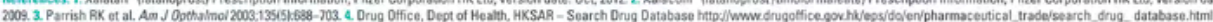

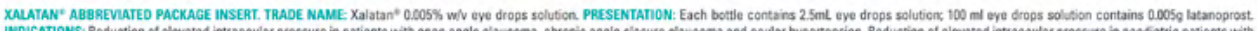

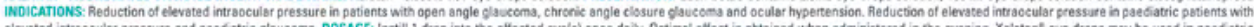

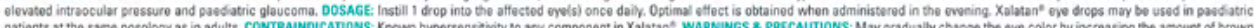
patients st the same posology as in adults. CONTRAUNOICANONS: Known hypersensitivity to any component in Xalatant. WARNiNGS \& PRECAUTIONS: May gradually change the eve color by increasing the amount of brown pigment in the inis. Patients should be monitored regularly and if the clinical situasion warrants, Xalazan" treatment may be discontinued. Xalatan* should be esed with caution in peri-operative peciod of cataract surgery patients, patients with a history of herpebic kerautis, aphakie pabents, in pseudophatic patients with torn posterior lens capsule or anterior chamber lenses, or in pubients with knowa risk factors for cystoid macular cedema, asthmatic patients. Experience to date shows that periorbital skin discolouration is not permanemt. Latanoprost may gradually champe evelashes and vellus hair in the treated eye and surrounding areas. Xalatan" contain. benzalkorium chloride. Contact lenses may sbsorb benzalkonium chloride and these should be removed before appiving Xalatan" but may be reinserted after 15 minutes. Ellicacy and safecty data in the age group < 1 year are

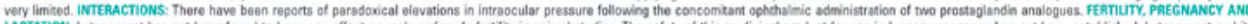
LACTarioN: Latanoprost hes not been found to have any effect on male or femele fertily in anima/ studes. The safeey of this medicinal product for use in human pregnency hes not been estabished. Latanoprost and its metabolites may pass into breast milk and Xalatan?" should therefore not be used in nutsing women of bresst feeding should be stopped. SiDE EFFECTs: Incteased iris pigmentation, mild to moderate conjunctival hyperaemila

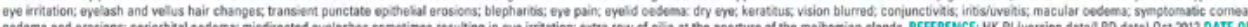

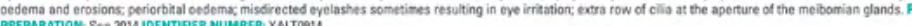

XULACOM" ABEAEVIATED PACKAGE INSERT. TRADE NAME: Xalacom" eye drops, solution 2.5mL, PRESENTATION: Each mi of Xalacom" contains 50meg latanoprost and $5 \mathrm{mg}$ timdlol. INDICATIONS: Reduction of imraoculat

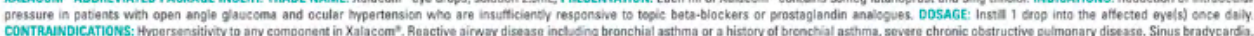

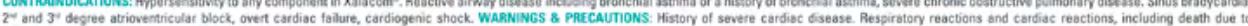

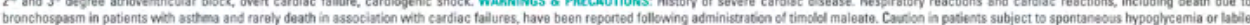

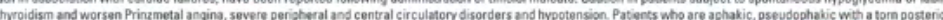
lens capsule or with known risk factors for macular oedema. Mary cause change in eve colour. Coenact lenses should be removed before asministration and mayte reinserted after 15 minutes INTERACTioNs: The use of twe

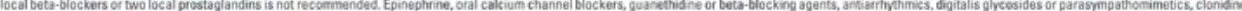

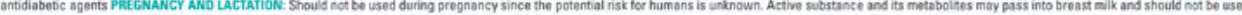

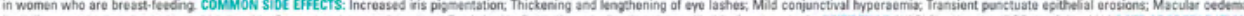

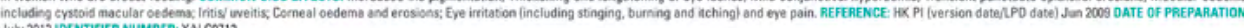
JUlY 2012 IOEENTFER NUMBBER: XALCO712

FULL PRESCRIBING INFORMATON IS AVAILABLE UPON REOUEST. 


\section{Asian Journal of}

Volume $13 \cdot$ Issue $4 \cdot 2014 \cdot 1560-2133$

www.asjoo.com www.kuglerpublications.com 